UDC $34.1 / 8$

LBC 67.91

\title{
THE COUNCIL OF EUROPE AND COOPERATION \\ IN THE FIELD OF PREVENTION AND LIQUIDATION OF CONSEQUENCES OF NATURALAND TECHNOLOGICAL DISASTERS
}

\author{
Valentina V. Lisauskayte \\ Irkutsk State University, Irkutsk, Russian Federation
}

\begin{abstract}
Introduction: the Council of Europe is a regional international organization, better known as a structure promoting the protection of fundamental human rights and freedoms, the fundamental principles of democracy and the rule of law. However, other activities are also carried out. Such work in the field of disaster protection is of interest. The purpose of the article is to study the special legal and organizational mechanism of the Council of Europe in this field. Methods: the methodological framework for this study is a set of methods of scientific knowledge, among which the main are the methods of historicism, systematicity, and analysis. Results: the paper presents the characteristics of Open Partial Agreement of the Prevention of, Protection Against and Organization of Relief in Major Natural and Technological Disasters of the Council of Europe. The author's and other scholars 'standpoints on this document and the theory of international law are reflected. The system of bodies and their interrelation for the solution of the general purposes and tasks is revealed. A special place is given to the description of the activities of the specialized centers operating within the particular states and included in the system of the centers under the Agreement. The individual projects of the member states, which are important for the preservation of human lives and reduction of the negative consequences for the economies of these countries, are analyzed. Conclusions: the study showed the effective cooperation for the member states and the organization itself, which is expressed in the implementation of various projects and programs. The latter is aimed at the formation of the national infrastructures, the involvement of science, the exchange of experience and the implementation of other activities in the medium-term action plan to improve the readiness of the countries and their populations to various types of disasters.
\end{abstract}

Key words: international cooperation on disaster protection, Open Partial Agreement of the Council of Europe, disaster prevention, OPA CE, disasters, protection against natural and technological risks, international protection against disasters.

Citation. Lisauskaite V.V. The Council of Europe and Cooperation in the Field of Prevention and Liquidation of Consequences of Natural and Technological Disasters. Legal Concept, 2018, vol. 17, no. 3, pp. 41-47. DOI: https://doi.org/10.15688/lc.jvolsu.2018.3.6

УДК $34.1 / 8$

ББК 67.91

\section{СОВЕТ ЕВРОПЫ И СОТРУДНИЧЕСТВО \\ В СФЕРЕ ПРЕДУПРЕЖДЕНИЯ И ЛИКВИДАЦИИ ПОСЛЕДСТВИЙ СТИХИЙНЫХ БЕДСТВИЙ И ТЕХНОГЕННЫХ КАТАСТРОФ}

\author{
Валентина Владо Лисаускайте \\ Иркутский государственный университет, г. Иркутск, Российская Федерация
}

Введение: Совет Европы является региональной международной организацией, которая больше известна как структура, продвигающая защиту основных прав и свобод человека, основы демократии и верховенства права. Однако в рамках нее осуществляются и другие виды деятельности. Интерес представляет такая 
работа в области защиты от бедствий. Целью статьи является изучение особого правового и организационного механизма Совета Европы в данной сфере. Методы: методологическую основу данного исследования составляет совокупность методов научного познания, среди которых основное место занимают методы историзма, системности, анализа. Результаты: в работе представлена характеристика Частичного открытого соглашения по прогнозированию, предотвращению и оказанию помощи в случае природных и техногенных катастроф Совета Европы. Отражена позиция автора и других ученых относительно данного документа и теории международного права. Раскрыта система органов и их взаимосвязь для решения общих целей и задач. Особое место уделено характеристике деятельности специализированных центров, функционирующих в рамках отдельных государств и входящих в систему центров в рамках Соглашения. Проанализированы отдельные проекты государств-участников, которые имеют важное значение для сохранения человеческих жизней и сокращения негативных последствий для экономик этих стран. Выводы: проведенное исследование показало эффективное для государств-участников и самой организации сотрудничество, выражающееся в реализации различных проектов и программ. Последние направлены на формирование национальных инфраструктур, вовлечение науки, обмен опытом и осуществление других видов деятельности в соответствии со среднесрочным планом действий для повышения готовности стран и их населения к различным видам бедствий.

Ключевые слова: международное сотрудничество по защите от бедствий, частичное открытое соглашение Совета Европы, предупреждение бедствий, ЧОС СЕ, бедствия, защита от природных и техногенных рисков, международная защита от бедствий.

Цитирование. Лисаускайте В. В. Совет Европы и сотрудничество в сфере предупреждения и ликвидации последствий стихийных бедствий и техногенных катастроф // Legal Concept = Правовая парадигма. 2018. - T. 17, № 3. - C. 41-47. - DOI: https://doi.org/10.15688/lc.jvolsu.2018.3.6

\section{Введение}

Совет Европы (далее СЕ) - региональная международная организация, известная как гарант защиты и продвижения прав и свобод, демократических механизмов. В то же время эта организация занимается различными формами деятельности, которые имеют опосредованное отношение к правам человека, однако не менее важны для развития государств. Такое взаимодействие осуществляется Советом Европы в рамках особого механизма - частичных открытых соглашений. Сотрудничество осуществляется и в сфере защиты от бедствий. Данное направление, хоть и не является традиционным для $\mathrm{CE}$, однако рассматривается как одно из наиболее успешных в своем развитии.

Одним из таких документов Совета Европы выступает Частичное открытое соглашение по прогнозированию, предотвращению и оказанию помощи в случае природных и техногенных катастроф (Open Partial Agreement EUR-OPA), принятое Комитетом министров Совета Европы 20 марта 1987 г. на 405-й встрече заместителей министров. Россия присоединилась к этому соглашению в 1989 г. [2, c.104]. На сегодняшний день соглашение объединяет 26 государств. В нем, помимо государств, принимают участие международные межправительственные и неправительственные организации: Европейское сообщество, ЮНЕСКО, Всемирная организация здравоохранения и гуманитарное отделение $\mathrm{OOH}$, Федерация Международного движения Красного Креста и Красного Полумесяца.

Интересной представляется позиция самого СЕ по данному вопросу. Согласно официальному сайту, «необходимо проводить различие между конвенциями СЕ и частичными соглашениями, которые являются не международными договорами организации, а лишь особой формой сотрудничества» [6]. Здесь необходимо уточнить, что $\mathrm{CE}$ в рамках реализации своих целей заключает конвенции для закрепления определенной группы прав и свобод их продвижения среди государств-членов и создания механизма их защиты. В то же время иной (не основной) формой деятельности является взаимодействие, в котором могут участвовать государства-члены по своему усмотрению, иные государства и международные организации. Такая деятельность основывается на положениях Устава Совета Европы и регламентируется специальным документом, именуемым «частичное открытое соглашение» (далее ЧОС). 
По мнению специалистов, это уникальная форма деятельности СЕ, во многом аналогичная деятельности в рамках программ Организации. Такое партнерство характеризуется эффективностью и многоплановостью, низким уровнем бюрократизации и высоким уровнем гибкости [1, с. 228]. Целью исследования выступает изучение этого регионального механизма в области защиты от бедствий, раскрытие его особенностей и проблем.

\section{Особенности}

\section{правового закрепления EUR-OPA}

\section{и его организационные элементы}

Частичное открытое соглашение - это самостоятельный механизм взаимодействия, который имеет свой бюджет и методы, определяемые участниками соглашения. Для начала такой деятельности необходимо получить разрешение Комитета министров СЕ на создание частичного соглашения, а также должна быть принята резолюция о его создании, в которой содержится устав соглашения, утвержденный его участниками.

Такой механизм был введен в практику Совета Европы еще в 1951 г., когда Комитет министров СЕ принял соответствующую резолюцию. Она была откорректирована уже в 1993 г. с учетом сложившейся практики сотрудничества в рамках частичных соглашений, что отразилось в содержании нового документа - Резолюции (93) 28 «О частичных и расширенных соглашениях» [3]. В этом документе отмечается, что опыт использования частичных соглашений Совета Европы как международно-правовой формы сотрудничества государств оказался успешен прежде всего потому, что частичные соглашения объединяли лишь заинтересованные государства [1, с. 230].

Участники соглашения взаимодействуют по вопросам изучения рисков бедствий, их предотвращению, управлению ими, а также по анализу посткризисной ситуации на пострадавшей территории и управлению ею. За 30-летнее существование данного направления деятельности в рамках Совета Европы сформировались отдельные блоки, самостоятельно функционирующие в рамках ЧОС. ЧОС СЕ (EUR-OPA) - это открытая группа сотрудни- чества, которая является адаптированным инструментом для продвижения проблематики уменьшения рисков бедствий в Европе и Средиземноморье [4, с. 2].

Исходя из содержания соглашения, изначально даже не были четко определены организационные структуры сотрудничества. Документ содержит указание на «встречу на уровне министров, которые проводятся конфиденциально» и на то, что «постоянные представители и эксперты проводят свои заседания в промежутке между встречами министров» [5]. В настоящее время мы имеем конкретный организационный механизм.

Организационно-управленческая деятельность осуществляется встречами министров частичного соглашения каждые 4 года. Такие встречи, при необходимости, могут проходить в виде специальных собраний более часто. Встречи проходят в закрытом формате. Вспомогательным органом является Комитет постоянных корреспондентов, который проводит встречи 1 раз в год с 2013 года.

Интересной представляется деятельность специально созданной структуры для реализации данного соглашения - Комитет постоянных корреспондентов. Его можно рассматривать как промежуточное звено между встречей министров и специализированными центрами. Комитет проводит свои заседания 2 раза в год для контроля за применением принятых руководящих принципов, подготовки совещания на уровне министров. По отдельным, более узким, вопросам и направлениям среднесрочного плана ЧОС в рамках встреч представляются доклады о состоянии ситуации в целом и ориентирах работы. Эта информация берется за основу и доводится до сведения специальных центров, Комитета министров для корректировки осуществляемых проектов.

Следует отметить, что сам текст документа не содержит конкретного регулирования механизма взаимодействия его участников. В договоре четко определены только виды сотрудничества и организационные вопросы функционирования совместного органа. В то же время анализ практики сотрудничества в рамках соглашения подтверждает сложившуюся систему активного научно-исследовательского взаимодействия, его важность 
и продуктивность. Рассматриваемое сотрудничество в сфере бедствий является ярким примером междисциплинарного взаимодействия для эффективного развития, что подчеркивается в самом соглашении.

Особенностью деятельности в рамках ЧОС и его отличие от других подобных региональных механизмов сотрудничества является то, что оно не предусматривает механизма реагирования на бедствия и проведение спасательных операций. Такая работа осуществляется в рамках двустороннего сотрудничества государств-участников. EUR-OPA на протяжении многих лет формирует и совершенствует систему информационного обмена для оценки масштаба бедствий, оповещения населения и обеспечения коммуникации между правительствами во время чрезвычайных ситуаций, а также содействует развитию системы «медицины катастроф» и психосоциальной подготовленности.

Одним из проектов в данном направлении является создание базы данных EXTREMUM. Это геоинформационная система, предназначенная для решения задач по предупреждению и ликвидации чрезвычайных ситуаций природного и техногенного характера в глобальном масштабе. В рамках программы проводится быстрая оценка возможного ущерба в течение короткого времени после произошедшего бедствия. Такая информация доводится до сведения властей пострадавшего государства, а также стран, которые могут оказать помощь в данной ситуации. Разработчиком является один из специализированных центров Соглашения - Европейский центр новых технологий по управлению основными природными и техногенными опасностями (в России известный как Bceроссийский научно-исследовательский институт по проблемам ГО и ЧС). С момента разработки и внедрения система EXTREMUM применялась при землетрясениях в России, Афганистане, Иране и Китае.

В 2016 г. в рамках состоявшейся в Португалии Министерской сессии был одобрен и представлен для согласования странам-участникам Среднесрочный план на 2016-2020 гг. «От слов к действиям: Европа и Средиземноморье на пути к высокой стойкости от природных и техногенных рисков». В рамках дан- ного плана определены применимые принципы и направления сотрудничества:

- борьба со всеми видами бедствий в комплексе;

- участие населения в программе снижения уязвимости;

- пересмотр и совершенствование национальных стратегий снижения опасности бедствий для адекватного реагирования на трансграничные риски;

- сотрудничество с другими международными организациями как ключевой элемент будущей работы в интересах синергизма и во избежание дублирования работы [8, p. 3].

На наш взгляд, одним из важных и приоритетных направлений определена популяризация культуры риска среди населения, подготовка населения к активному участию в стратегии риска бедствий. В ранее действовавшем плане было закреплено направление «создание культуры противодействия рискам». Оно реализовывалось в том числе посредством информирования населения о совершенствовании защиты от рисков и более эффективном противодействии опасностям при чрезвычайных ситуациях. Специально для этого был создан сайт BeSafeNet, который носит информационный характер и содержит основную информацию о бедствиях природного и техногенного характера. Реализацией данного проекта занимается Европейский центр по предупреждению стихийных бедствий с использованием Интернета (Кипр).

Целью является создание единой сети по предоставлению обучающего материала для повышения культуры безопасности среди населения. Первый этап - работа со школьниками. В настоящее время портал больше похож на электронный учебник информативного характера об опасностях бедствий и возможности избежать последствий. Однако у Центра большие планы относительно своего развития с точки зрения содержания и с точки зрения распространенности на все 26 стран ЧОС. Данный проект можно рассматривать именно как вспомогательный ресурс для учебных заведений, где они могут в режиме онлайн ознакомиться с материалами, пройти тестирование. Информация на сайте представлена на всех официальных языках Соглашения. 


\section{Деятельность} специализированных центров EUR-OPA

«Знание рисков как основа государственной политики, более глубокое знание источников риска является первым шагом в разработке соответствующих профилактических мер и адекватных мер по обеспечению готовности. Обзор и выявление существующих пробелов в знаниях позволит получить лучшеепонимание существующих рисков» $[8$, p. 5].

Такую работу в рамках Соглашения осуществляют 27 специализированных центров. Соглашение является платформой сотрудничества в области большинства природных и техногенных бедствий между Восточной Европой, Южным Средиземноморьем и Западной Европой.

Специализированные центры - это учреждения конкретных государств, которые являются участниками ЧОС. Они разрабатывают проекты (как на национальном, так и на региональном уровне), направленные на повышение осведомленности и устойчивости к основным рискам среди населения. Центры имеют разную юридическую форму: образовательные, исследовательские учреждения, государственные научно-исследовательские институты, общественные организации. В сфере своих направлений деятельности они проводят межгосударственные мероприятия, конференции и встречи. Конкретные проекты сначала апробируются на уровне своего государства, а затем представляются другим странам для внедрения в рамках реализации сотрудничества по Соглашению.

Один раз в год проходит Совещание директоров центров, где обсуждаются вопросы и проблемы по реализации среднесрочного плана, определяются приоритетные направления на ближайший год с учетом международных мероприятий, деятельности ООН. Часто эти встречи проходят совместно с Комитетом постоянных корреспондентов.

Рассмотрим деятельность некоторых центров для формирования представления о функционировании всей системы взаимодействия.

На основе Частичного открытого соглашения в Греции был создан Европейский центр предотвращения бедствий и прогнозирования землетрясений [7]. Практика показывает, что основным видом деятельности группы сотрудничества являются различные научные исследования в области катастроф, особенно природных, с целью усовершенствования концепции защиты от них. Греция, как место создания одного из европейских сейсмоцентров, выбрана не случайно. Она расположена в одном из эпицентров сейсмической активности района Средиземноморья. Подтверждением активной деятельности греческого центра является участие в создании карты сейсмического риска данного региона, которая построена на основе проведенных исследований и с учетом разброса возможной магнитуды землетрясений, характерной для конкретной территории.

Еще одно направление сотрудничества на ближайшие годы взаимодействия участников ЧОС - трансграничные риски, относительно которых они должны определить технические, административные вопросы, которые создают препятствия в борьбе с бедствиями. Целью должна стать гармонизация национального законодательства и национальных платформ управления рисками бедствий для облегчения реагирования, его оперативности и повышения качества совместного управления трансграничными рисками.

Одним из проектов в данном направлении является борьба с трансграничными лесными пожарами, реализация которого была начата еще в 2011 году. В рамках совместной работы нескольких специализированных центров Германии, Греции, Македонии и Европейской экономической комиссии ООН было разработано типовое соглашение о трансграничном сотрудничестве в области управления пожарами. Проведенные совместные исследования подтвердили, что государствам необходимо решать проблемы, связанные с экологией, климатическими и социально-экономическими изменениями, негативно отражающимися на состоянии лесов. Государственная политика, затрагивающая лесные пожары, должна быть рассмотрена и адаптирована к этим изменениям. А международное сотрудничество в области пожаротушения должно быть направлено на обмен опытом и повышение эффективности сотрудничества в чрезвычайных ситуациях. Разработанное типовое соглашение должно способствовать такому взаимодействию государств-участников. 


\section{Выводы}

Представленная характеристика реализации конкретного Частичного открытого соглашения Совета Европы позволяет сделать следующие выводы:

1. Совет Европы разработал и активно применяет достаточно специфическую технологию международного взаимодействия, в основе которой лежит некий документ, не рассматриваемый самой организацией и специалистами в качестве международного договора, но определяющий предмет и основные формы сотрудничества участников. В качестве последних выступают не только государства - члены СЕ, но и иные, любые страны, пожелавшие присоединиться к такому проекту, а также международные организации и иные заинтересованные структуры.

2. Участники ЧОС не имеют жестких международных обязательств. Они сами определяют для себя среднесрочный план работы, методы взаимодействия и ожидаемые результаты.

3. Рассмотренное Частичное открытое соглашение СЕ по прогнозированию, предотвращению и оказанию помощи в случае природных и техногенных катастроф является одним из примеров эффективного регионального сотрудничества, в основе которого лежат научно-технические разработки и стремление участников к их внедрению.

4. Такой механизм международной деятельности абсолютно аполитичен, в отличие от базовых сфер деятельности самой организации Совета Европы. Вне зависимости от происходящих между государствами-членами событий сотрудничество интенсивно реализуется и имеет свои результаты, которые в дальнейшем применяются и на более глобальном уровне.

5. Конечно, как любой межгосударственный механизм, он не лишен недостатков и проблем. Однако в большинстве своем они носят рабочий характер, и участники стремятся к их разрешению.

6. На наш взгляд, ЧОС является одним из позитивных примеров совместной работы без внешних, жестких обязательств, что может быть использовано в качестве примера для иных региональных структур и, возможно, всего мирового сообщества.

\section{СПИСОК ЛИТЕРАТУРЫ}

1. Алисиевич, Е. С. Частичные соглашения как форма сотрудничества государств в рамках Совета Европы / Е. С. Алисиевич // Московский журнал международного права. - 2009. - № 2. - С. 228-243.

2. Безопасность населения, территорий и хозяйственных объектов : сб. междунар. соглашений по вопросам гражданской обороны, предупреждения и ликвидации последствий чрезвычайных ситуаций. Вып. 2 / вступление С. К. Шойгу. - М. : ИздАТ, 1996. $-105 \mathrm{c}$

3. Резолюция Комитета Министров Совета Европы 1993 г.№ (93) 28 «О частичных и расширенных соглашениях». - Электрон. текстовые дан. Режим доступа: http//www.coe.int/t/cm/home_en.asp/ (дата обращения: 10.02.2018).

4. Среднесрочный план на 2011-2015 гг. : принят на 12-й министерской сессии «Европейское и Средиземноморское соглашение о крупных катастрофах (ЧОС - СЕ)» в Санкт-Петербурге (Российская Федерация), 28 сент. 2010 г. : АР/САТ (2010) 05 rev. 2. Or. Е. - Электрон. текстовые дан. - Режим доступа: https://www.coe.int/t/dg4/majorhazards/ ressources/Apcat2010/StPetersburg/APCAT2010 05rev2_MediumTermPlan2011-2015_RU.pdf. - Загл. c экрана. -9 c.

5. Частичное открытое соглашение по прогнозированию, предотвращению и оказанию помощи в случае природных и техногенных катастроф. 1987 г. - Электрон. дан. - Режим доступа: http:// www.coe.int/en/web/conventions/partial-agreements//conventions/ap/list?p_auth=gVop2e9E (дата обращения: 10.02.2018).

6. Council of Europe : [site]. - Electronic data.Mode of access: http://www.coe.int (date of access: 10.02.2018).

7. European Centre on Prevention and Forecasting of Earthquakes : [site]. - Electronic data. Mode of access: http://ecpfe.oasp.gr (date of access: 10.02.2018).

8. Medium term plan 2016-2020: From words to actions: towards a European and Mediterranean region more resillent to natural and technological risks : adopted at the 13ed Ministerial Session of the European and Mediterranean Major Hazards Agreement(EUR-OPA), 2016.-Electronic data. - Mode of access: https://rm.coe.int/16806b7fb6. - Title from screen. -9 p.

\section{REFERENCES}

1. Alisievich E.S. Chastichnye soglasheniya kak forma sotrudnichestva gosudarstv v ramkakh Soveta Evropy [Partial Agreements as a Form of States 
Cooperation within the Council of Europe]. Moskovskiy zhurnal mezhdunarodnogo prava, 2009, no. 2, pp. 228-243.

2. Shoygu S.K. Bezopasnost naseleniya, territoriy $i$ khozyaystvennykh obyektov: sb. mezhdunar. soglasheniy po voprosam grazhdanskoy oborony, preduprezhdeniya $i$ likvidatsii posledstviy chrezvychaynykh situatsiy. Vyp. 2 [Safety of Population, Territories and Economic Objects: Collection of International Agreements on Civil Defense, Prevention and Elimination of Emergency Situations Consequences]. Moscow, IzdAT Publ., 1996. 105 p.

3. Rezolyutsiya Komiteta Ministrov Soveta Evropy 1993 g. № (93) 28 «O chastichnykh $i$ rasshirennykh soglasheniyakh» [Resolution of the Committee of Ministers of the Council of Europe of 1993 No. (93) 28 'On Partial and Expanded Agreements']. URL: http//www.coe.int/t/cm/home en.asp/ (accessed 10 February 2018).

4. Srednesrochnyy plan na 2011-2015 gg.: prinyat na 12-y ministerskoy sessii «Evropeyskoe $i$ Sredizemnomorskoe soglashenie o krupnykh katastrofakh (ChOS - SE)»v Sankt-Peterburge (Rossiyskaya Federatsiya), 28 sent. $2010 \mathrm{~g}$. [Medium-Term Plan for 2011-2015: Adopted at the $12^{\text {th }}$ Ministerial Session 'The European and Mediterranean
Agreement on Large Accidents' in St. Petersburg (Russian Federation), September 28, 2010]. URL: https:// www.coe.int/t/dg4/majorhazards/ressources/ Apcat2010/StPetersburg/APCAT2010_ 05rev2 MediumTermPlan2011-2015_RU.pdf.

5. Chastichnoe otkrytoe soglashenie po prognozirovaniyu, predotvrashcheniyu i okazaniyu pomoshchi $v$ sluchae prirodnykh i tekhnogennykh katastrof. $1987 \mathrm{~g}$. [The Partial Open Agreement on Forecasting, Prevention and Assistance in Case of Natural and Technogenic Catastrophes. The Year of 1987]. URL: http://www.coe.int/en/web/conventions/ partial-agreements/-/conventions/ap/list?p_ auth $=\mathrm{gVop} 2 \mathrm{e} 9 \mathrm{E}$ (accessed 10 February 2018).

6. Council of Europe. URL: http://www.coe.int (accessed 10 February 2018).

7. European Centre on Prevention and Forecasting of Earthquakes. URL: http://ecpfe.oasp. gr (accessed 10 February 2018).

8. Medium term plan 2016-2020: From words to actions: towards a European and Mediterranean region more resilient to natural and technological risks: adopted at the $13^{\text {th }}$ Ministerial Session of the European and Mediterranean Major Hazards Agreement (EUR-OPA), 2016. URL: https://rm.coe.int/ $16806 \mathrm{~b} 7 \mathrm{fb} 6$.

\section{Information about the Author}

Valentina V. Lisauskayte, Candidate of Sciences (Jurisprudence), Associate Professor, Department of International Law and Comparative Jurisprudence, Irkutsk State University, Ulan-Batorskaya St., 10, 664082 Irkutsk, Russian Federation, vlado@mail.ru.

\section{Информация об авторе}

Валентина Владо Лисаускайте, кандидат юридических наук, доцент кафедры международного права и сравнительного правоведения, Иркутский государственный университет, ул. УланБаторская, 10, 664082 г. Иркутск, Российская Федерация, vlado@mail.ru. 